\title{
CONVERSAS COM UM ESPELHO: \\ Transbordamentos no ensino da arte
}

Maria Cristina Diederichsen

\section{Resumo}

Este artigo visa dar alguns passos por entre as descontínuas, incertas e sinuosas paisagens da contemporaneidade, onde o virtual e o real se interpenetram, diferentes olhares se cruzam, múltiplos discursos se tocam. Uma conversa acontece entre uma professora de arte e um espelho, pensando o ensino da arte como possibilidade de criação de outros devires, outras sensibilidades, de novas maneiras de viver, de ser-em-grupo e de potencialização poética do processo de aprender. Diante/dentro da crise em que nos encontramos como inventores de mundos e construtores da herança que, inevitavelmente, deixamos aos que nascem depois de nós, o ato artístico pode criar estranhamentos, gerar descontinuidades, olhares enviesados, questionar as maneiras habituais de percepção, e, como quem vive cada momento, cada vez como a primeira vez, inaugurar um novo tempo, produzindo diferenças, liberdades e possibilidades de encontro.

\section{Palavras-chave}

deslocamento, o outro, linguagem, imagem

\begin{abstract}
This article aims to take a few steps through the discontinuous, uncertain and winding contemporary landscapes, where the virtual and the real interpenetrate, different perspectives intersect and multiple discourses touch each other. A conversation happens between an art teacher and a mirror, thinking of art education as a means of creating other becomings, other sensitivities, new ways of living, of being "in group" and of a poetic potentializing of the process of learning. Before the crisis we find ourselves as inventors of worlds and builders of the inheritance which we inevitably leave to those who are born after us, the artistic act can create estrangements, generate discontinuities and oblique views, question the habitual ways of perception and, as those who live every moment, every time, like the first
\end{abstract}


time, inaugurate a new time, producing differences, freedoms and possibilities of meeting.

Keywords

displacement, the other, language, image

\section{Chegada}

Não haverá nunca uma porta. Estás dentro e o alcácer abarca o universo. E não tem anverso nem reverso. Nem externo muro nem secreto centro. Não esperes que o rigor de teu caminho que teimosamente se bifurca em outro, tenha fim.

Jorge Luis Borges

-Bom dia espelho!

-Bom dia...

-Não dá para você me refletir uma cara melhor hoje?!

-Os espelhos são vazios e abertos. Não retêm o que refletem. Não elegem, nem recusam...

-De onde estou olhando? Com que olhos? Não sei...

-Houve até muitas pessoas que se afogaram num espelho... ${ }^{1}$

-Olho. Se pensar que sei, não verei. Para ver, me afasto do conhecido... Não sei... Não tenho respostas... Mas "este não sei não é resultado da ignorância, do ceticismo, nem do niilismo, nem de obscurantismo. Esse não-conhecimento é uma condição necessária para que alguma coisa aconteça, para que seja assumida uma responsabilidade, para que uma decisão seja tomada." ${ }^{2}$

-"Ver supõe a distância, a decisão separadora, o poder de não estar em contato e de evitar no contato a confusão. Ver significa que essa separação tornou-se, porém, reencontro."3

\footnotetext{
${ }^{1}$ GOMES DE LA SERNA, apud BACHELARD, G. 2002, p.21.

${ }^{2}$ DERRIDA J. apud SKLIAR, 2008, p.21.

${ }^{3}$ BLANCHOT, M. 1987, p. 22.6
} 


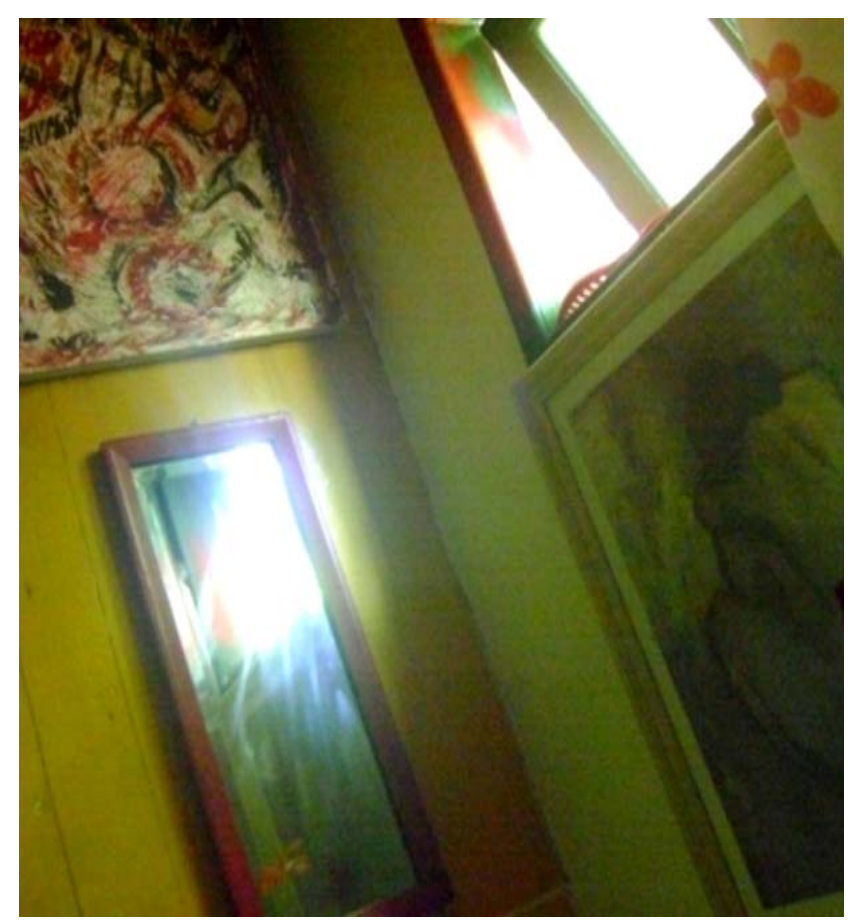

Figura 1- Foto M. C. Diederichsen tim, 2011.

-Estar, simultaneamente, perto e longe, num local determinado e em outro tempo, outro lugar?

-Os lugares só podem ser tocados por procedimentos que os deslocalizam, o tempo só pode ser pensado por meio do anacronismo. ${ }^{4}$

-Então ajude-me a deslocalizar minha aula de arte! A deslocar meu tempo dentro da escola!

-As crianças é que fazem isto bem... Elas são os nossos professores... Seguem criando outros tempos, outros espaços, outras brincadeiras.

-É difícil largar minhas referências e abrir-me para as delas...

-Existe outro caminho?

-Não sei... Percebo que é importante que eu aprenda com elas... Que minha atuação como educadora, seja inspirada pelas perguntas, pelos desejos, pelo interesse delas. Não quero sugerir que passem a ser reproduções de um modelo caduco...

${ }^{4}$ CHEREM, R. 2010, p.257. 
-Quando há troca, participação ativa, possibilidades de criação, as pessoas se mantém vivas, interessadas, entusiasmadas... Ensinar pode ser reconstruir as modalidades do ser-em-grupo! ${ }^{5}$

-Sim. Quando construímos coletivamente as aulas, os estudantes não se dispersam tanto, sempre surge algo diferente, algo novo. A cada momento uma invenção...

-Um encontro... E o tal "domínio sobre a turma"?

-Quando eles percebem que aprendo com eles, ficam motivados a crescer, a continuar aprendendo a se responsabilizar por seu próprio aprendizado... Não há necessidade de "dominá-los." Afinal, a aprendizagem é um processo sobre o qual não se pode exercer controle: nunca se sabe de antemão como alguém vai aprender - que amores tornam alguém bom em arte, por meio de que encontros, se é músico, ou geógrafo, em que dicionários se aprende a pensar... ${ }^{6}$

-A criação é por natureza imprevisível... e a cognição, provisória...

-Quando aprender deixa de ser um ato de criação, o aprendizado se torna insípido, perde sua potencia, desfalece.

-Conhecer e criar, simultaneamente... Uma receptiva atividade.

-Principalmente na arte... Conhecer criando... Uma experiência diferente daquela que se rege por um pensar entronizado, governado pelo entendimento. Procuro pensar o conhecimento como uma atividade agudamente atenta a sua própria abertura, a sua própria suscetibilidade, a seu próprio poder de ser afetada pelas ondulações do campo problemático em que ela compõe suas veredas, suas andanças, suas passagens, seus intervalos. O conceito de cognição é intensificado e expandido pela sensibilidade e pela criação, que Ihe conferem dinamismo, potências de devir, geram movimentos, problematizam o que se encontra instituído, expandem e surpreendem, dobram, redobram e desdobram realidades. ${ }^{7}$

-llusões envolvem o conhecimento. Miragens do pensamento. Explicam-se pelo peso do nosso cérebro, pela circulação estereotipada das opiniões dominantes, e porque não podemos suportar esses movimentos infinitos. Há, de início a ilusão de transcendência, que talvez preceda todas as outras. Depois a ilusão dos universais.

\footnotetext{
${ }^{5}$ GUATTARI, F. 1990, p. 16.

${ }^{6}$ DELEUZE, G . 2009, p.237.

${ }^{7}$ KASTRUP, V. 2007, p12-13.
} 
Depois ainda, a ilusão do eterno, quando esquecemos que estes são apenas conceitos e, que foram em algum momento criados. ${ }^{8}$

-A perda das estruturas estáveis, dos fundamentos absolutos e unívocos, apontou brechas na tela do conhecimento, novas possibilidades e concepções de liberdade, trazendo para e educação diversos desafios. Sinto-me confrontada com a necessidade de criar novas formas de construir e compartilhar sensibilidades e (não) saberes, de aprender a lidar com minhas dificuldades em transformar as formas de fazer educação, tão ligadas à reprodução dos modelos de estratificação, competição, exclusão, controle, dominação, que caracterizam as práticas econômicas em nossa sociedade. Quero inventar práticas que ultrapassem os condicionamentos, os limites, que saibam pensar também o fora...

-Voar e pousar, voar com os pés no chão... Criar outros chãos...

-Continuo buscando criar possibilidades e tempos de olhar, tocar, pensar, sentir, transformar as inquietações e desafios que vivemos, na escolas, nas sociedades, no mundo, diante/dentro desta cultura que se transforma tão rapidamente, se tornando uma "cultura-mundo, do tecnocapitalismo planetário, das indústrias culturais, do consumismo total, das mídias e das redes digitais." Diante/dentro destas terras desterritorializadas, incertas, plurais, onde o virtual e o real se interpenetram, diferentes olhares se cruzam, múltiplos discursos se tocam e se transformam, tecendo redes instáveis, gerando inseguranças e também possibilitando novas maneiras de estar e recriar nosso mundo. Diante/dentro de fogos, águas, ares devastadores, que descobrem casas, florestas e mares, descobrem desejos e nossos corpos que continuam vibrando. Diante/dentro "da força da grana que ergue e destrói coisas belas, da feia fumaça que sobe, apagando as estrelas" ${ }^{10}$ e o espaço infinito que (não) somos. Diante/dentro de nossos modos de conviver: afetos possessivos, dominadores, aproximações, isolamentos, torres, porões, carinhos.

-Risos e murmúrios brotam a cada gesto, rompendo cercas e calçadas, escorregando por estas brechas, cavando aberturas, transformando-nos em

\footnotetext{
${ }^{8}$ DELEUZE, G. e GUATTARI, F. 1992, p. 67.

${ }^{9}$ LIPOWETSKY, G, e SERROY, 2011, p. 7.

${ }^{10}$ VELLOSO, C. Sampa.
} 
singulares e coletivas mãos, em próximos e distantes ouvidos, em grandes e pequenos olhos.

-Diante/dentro da crise em que nos encontramos como inventores de mundos, de nós próprios e, construtores da herança que, inevitavelmente, deixamos aos que nascem depois de nós. Continuo buscando criar outros devires, possibilitar a percepção de novas paisagens, esquinas, desvios, deslumbramentos. (Educar?)

-Penso que sim... "Não estamos no mundo, tornamo-nos com o mundo, nós nos tornamos, contemplando-o. Tudo é visão, devir. Tornamo-nos universo."11

-Criamos a partir de uma perspectiva nômade, a serviço da liberdade.

-As tramas de permanência do mundo, dos conceitos, das idéias, rasgam-se a partir da transitoriedade de todos os fenômenos. Cada instante devora o precedente, viver e morrer são uma unidade. ${ }^{12}$ Criação e destruição apresentam-se de forma justaposta. Para criar é necessário, por assim dizer, também morrer. Morte ampla, metafórica e parcial. Morte de nossas cascas, de nossas prisões. A vida é um passeio continuamente passando.

-Nas aulas de arte busco, junto com os alunos, passear por entre linhas, cores, formas, pelas vozes que nos habitam... As que falamos, calamos, escutamos... Por entre poéticas que, talvez, não perceberíamos, fechados que (tantas vezes) estamos, de estreitos mundinhos, adestrados, anestesiados; ensurdecidos que estamos de tantos sons ou de tão poucos, sempre repetidos; áridos que estamos de apequenados e afastados de sensibilidades e delicadezas; assustados que estamos, de crueldades e indiferenças; desacreditados que estamos, de não acreditarmos no mundo, na vida, ou em nós; desapossados que estamos de nossas potencialidades, que (tantas vezes) pouco agimos... Vozes que falam nas entrelinhas, vozes que se dizem, se dão a escutar, insistem, teimam... Vozes que falam desde o lugar desta teimosia... desde o lugar onde vivemos, inventamos, compartilhamos.

-Falas múltiplas, de múltiplos personagens, por vezes desconexas; pensamentos, percepções e afetos que se entrecruzam, se beijam, se contaminam, se espalham para além da tirania de uma estabelecida, coerente e longa voz, tida como bem formada e contínua, a única justa.

\footnotetext{
${ }^{11}$ DELEUZE, G. e GUATTARI, F. 1992, p. 220.

${ }^{12}$ NIETZSCHE, 1988 , p 45.
} 
-Falas que se questionam e questionar é pensar interrompendo-se... ${ }^{13}$ -É reconhecer que a fala é necessariamente plural, capaz de manter a diferença, fala que segue caminhando, visitando paisagens, intervalos, amores, formas, cores, percorrendo vazios sempre plenos, inventando o dia, a noite, a vida...

-Trata-se de liberar a vida lá onde ela é prisioneira, ou tentar fazê-lo, num combate incerto. ${ }^{14}$ Vivos que estamos, ainda criadores. Falar assim... Mas... o que fazer?

\section{Peles, pedras e aberturas}

O que é a realidade sem a energia deslocadora da poesia? René Char

-Proponho que hoje sejamos abertos, não atores de um julgamento, de uma sujeição, de uma intimidação, procuradores de uma Causa. ${ }^{15}$ Que busquemos dissolver a proteção com a qual, em vão, tentamos mascarar, com o rótulo, o cálculo e o projeto, este infinito vão. Acolher nossa vastidão, viver... juntos... poeticamente... -Estou tão atrapalhada! não sei...bem que tento...porém....me pergunto.... Olhe a nossa volta... Como acolher esta barbárie? Sinto-me numa terra estranha... Como viver "poeticamente juntos" se não consigo nem sair de mim, destes espaçosmercados marcados pela ganância, pelas divisões de trabalho, pelas leis do lucro, do espetáculo? Estes espaços me controlam com suas técnicas de sedução e sujeição cada vez mais sofisticadas, decompõem meus vínculos afetivos, meus desejos... Não sei se quero...ou não...

-Viver o desconhecido, acolher o inusitado... Não é fácil... Mas, maravilhoso. Um desafio... Criar outras formas de habitar estes espaços e, mesmo dentro deles, estar fora deles... Não deixar nossas mentes, percepções, emoções, aprisionadas no lugar-comum, no clichê. ${ }^{16}$

-Difícil... Olhar, enxergar, se libertar dos hábitos... (Dá tanto trabalho...)

\footnotetext{
.13 BLANCHOT, 2010, P 86.

${ }^{14}$ DELEUZE, G. e GUATTARI, F. 1992, p. 222.

${ }^{15}$ BARTHES, R. 2004, p 331.

${ }^{16}$ Idem, p.29.
} 


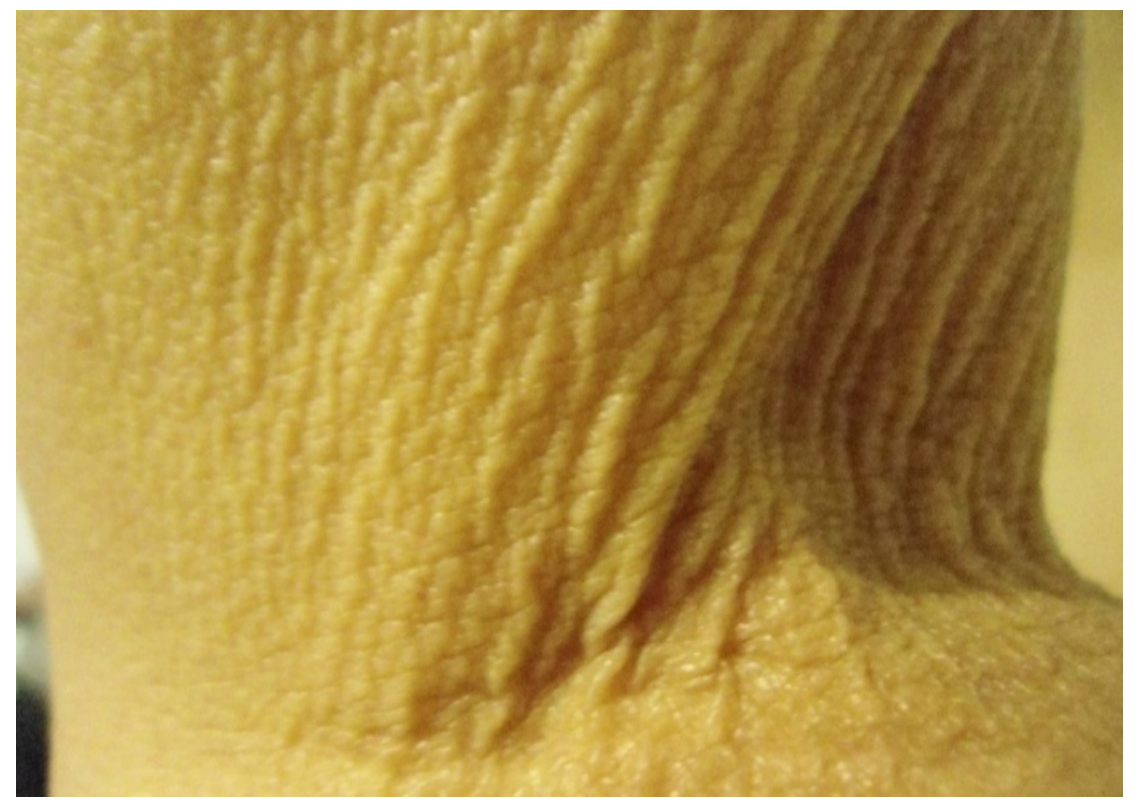

Figura 2- Auto-retrato. Foto M. C. Diederichsen tim 2011.

-Viver arte. Colocar-se na pele das coisas, não para compreendê-las, mas para animá-las, fazendo seus afectus ${ }^{17}$ crescerem e devirem a energia vinculadora das relações. O mundo, espelhado pela criação artística, deixa de ser uma simples materialidade, convertendo-se num potencial e diversificado corpo de relações significativas. ${ }^{18}$ Nos colocamos na pele do mundo... O mais profundo é a pele... ${ }^{19}$ -Ah... Pele? Você nem sabe como me sinto em minha pele... (tão pequena!) Aprender e ensinar nesta escola... Sinto-me (...?). Como propiciar experiências artísticas criadoras num ambiente tão cheio de restrições? Burocracia, autoritarismo, violência, visão estreita, o salário para lá de baixo, dá para aguentar? Às vezes, o mundo todo me parece transformado em pedra... como se ninguém pudesse escapar do olhar inexorável da Medusa...

-Você se refere ao mito da Medusa com cabeça de serpentes?

$-\operatorname{Sim} . .$.

-E Perseu? Onde está?

-Não sei...

\footnotetext{
${ }^{17}$ DELEUZE G e GUATARRI, F. 1992, p. 213.

${ }^{18}$ MEIRA,M. p.133.

${ }^{19}$ VALERY, P, apud MACHADO, R. 2009, p.35.
} 
-Para vencer a Medusa sem se deixar petrificar, Perseu se sustenta sobre o que há de mais leve, as nuvens e o vento, e dirige o olhar para aquilo que só pode ser visto com uma visão indireta, por uma imagem capturada num espelho. ${ }^{20}$

-Posso enxergar neste mito, uma alegoria da relação do professor-artista com seu trabalho... Impossível olhar diretamente a realidade, a dureza pode nos transformar em pedra. Criamos olhares poéticos, escudos/espelho, recurso artístico, visadas enviesadas...

-Um olhar que vê o que seria invisível para um olhar comum. ${ }^{21}$

-Como atravessar o cotidiano escolar com este olhar?

-Talvez tentando "em meio ao delírio do mundo, caminhar como a beira de um lago plácido, não com indiferença, mas com inocência, até um destino, uma escolha. Não resistir ao apequenamento das coisas e das pessoas. Deslocar-se. Reaprender. Respirar liberdade frente ao peso da orfandade." Caminhar diante do peso das coisas, com a leveza na alma. ${ }^{22}$

-Será que isto é um auto-engano, um escapismo?

-É apenas a afirmação da possibilidade de encontros e outras formas de se estar no mundo. Formas de viver e não apenas sobreviver. Fazer da percepção poética e da atitude ética uma decisão de vida. "Talvez o compromisso ético, percebido no nosso mundo como ridiculamente anacrônico, seja mais subversivo do que qualquer outra ação."23

-Parece meio inocente... Ou insuficiente...

-Uma inocência sem ingenuidade. ${ }^{24}$

-É ingênuo achar que um ato ético possa combater o que há de feio, de cruel... Nossa responsabilidade é...

\footnotetext{
${ }^{20}$ CALVINO, I. 1991, p. 16

${ }^{21}$ MEIRA, M. 2009, p.123.

22 LOPES. D. 2007, p.77, 78.

${ }^{23}$ ZIZEK, in LOPES, D. p.56

${ }^{24}$ LÈVINAS, E. 2003, p98.
} 
-“Não quero fazer guerra ao que é feio. Não quero acusar, não quero nem mesmo acusar os acusadores.

-Faço tantos julgamentos...sem perceber... Que a minha única negação seja desviar o olhar! Quero ser, algum dia, apenas alguém que diz sim!"25

-Começamos com um sim... Acolhemos nossa herança, o outro. Travamos com ela uma relação amorosa. Penetramos em suas vielas, desfazemos suas identidades, seus binarismos, suas oposições, seus bonitos e feios, ricos e pobres, próximos e distantes e, suas negações desses segundos termos. Não mais dualismos, mas multiplicidades... Desconstruímos nossa herança e a reconstruímos em uma paisagem da diferença. ${ }^{26}$

-Acho que prefiro negar esta herança...

-E fazer o que? A partir do que? Vais negar as palavras com que pensas e falas? Sinto-me herdeiro... Herdei o que pretendo, agora, desconstruir.

-Desconstruir é negar?

-É um gesto de alguém que diz sim, e não de alguém que desconfia do outro, o nega e o condena desde o lugar ressentido do deserdado. "A desconstrução é um gesto de afirmação, um sim originário que não é crédulo, dogmático ou de consentimento cego, otimista, confinado, positivo." ${ }^{27}$ Nossa herança não é fixa, imóvel, verdadeira... Está se movendo, nos levando para um outro lugar, "para um lugar que nós não sabemos, para um lugar não conhecido, para o lugar do não conhecimento." ${ }^{28}$

-O trabalho com arte me propicia certa liberdade frente as formas habituais de percepção...

-Coragem para ir se abrindo, se entregando nas mãos da vida e, aprender a confiar? -Aprender a confiar? Prezo minhas armaduras... (ai! que peso!) Hay que endurecerse...

-Sim e... Aprender a desconfiar...das certezas!

$-\ldots ?$ !

\footnotetext{
${ }^{25}$ NIETZSCHE, F. 2002, p. 188.

${ }^{26}$ DERRIDA, J. 2004, p. 9.

${ }^{27}$ DERRIDA, J. 2004, p.66.

${ }^{28}$ SKLIAR, 2008, p.19.
} 
-Acolher o que vem é recriá-lo, torná-lo novo de novo, transformá-lo num acontecimento.

-Sim... Somos nós os instauradores de mundos, os criadores de terras.

-A cada momento, a cada olhar, damos nascimento a um mundo...

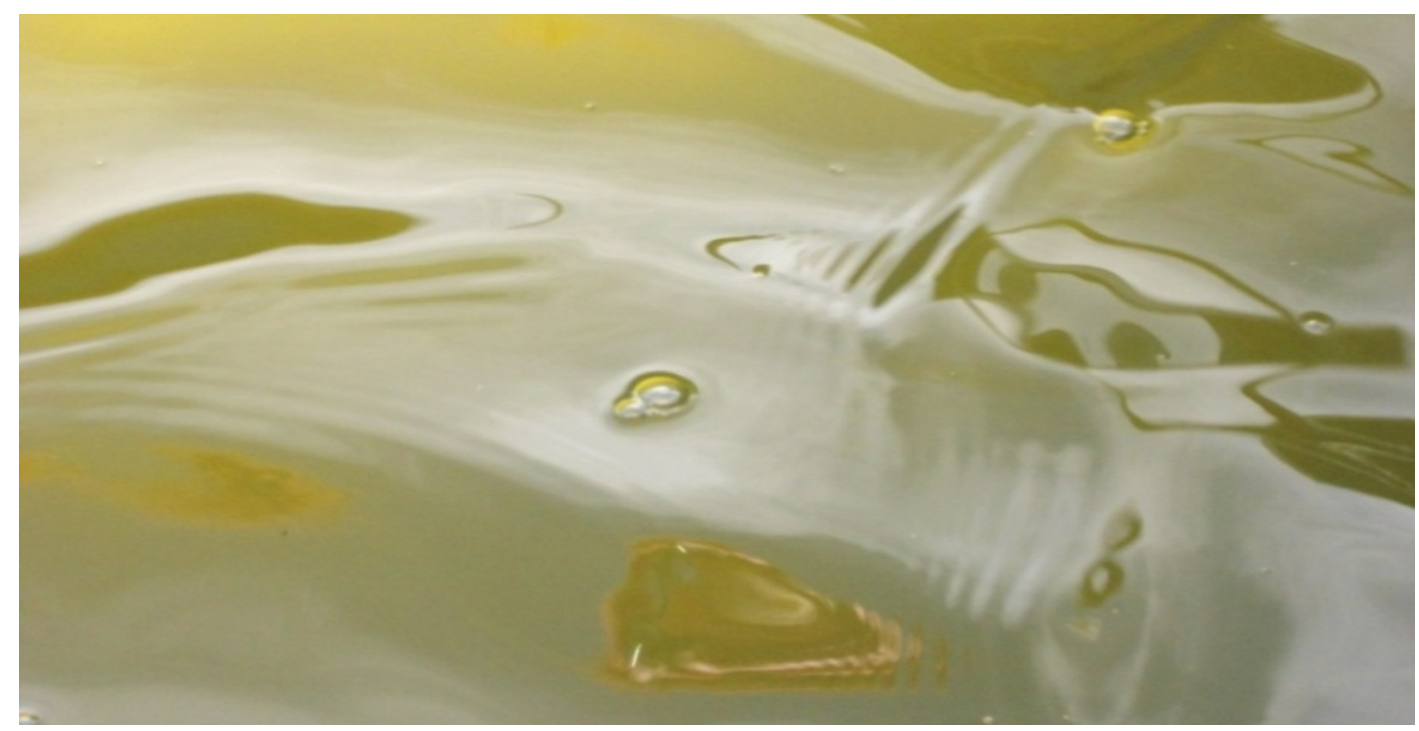

Figura 3- Emergência foto M.C. Diederichsen

-(O que tenho instaurado com meu olhar?) Respirar poesia: na amplidão do céu, no balançar das árvores, no ruído dos carros, nas vozes das crianças, nos problemas da escola, nas línguas tagarelas e nas famintas, no dia que nasce, na noite que abraça tolos, sábios, prédios, montanhas e mares... No sorriso dos jovens, dos velhos, dos distantes, no gramado onde deito, chão sem chão... Até na estupidez do arrogante, nos corredores panópticos, na aspereza que fere... escuto o pulsar dos corações, o silêncio e o espaço. Esta é minha forma de arte. A criação artística não se deixa capturar nas malhas da cultura nem se conter na estreita armadura da lógica. Capta a vida, o instante em um frescor nunca antes vivido. Abre espaços, amplidões, instala mundos. Toca a abertura, qualidade básica da existência, anterior à dimensão cultural. Abertura não como um domínio superior, mas como aquilo que dá lugar ao mundo.

-Legal... Como compartilhas isso? Crias linguagens que toquem sentidos?

-Tento criar linguagens que deixem pausas, escutas, recolhimentos e liberdades. Linguagens que nos possibilitem retirarmo-nos de nós mesmos, migrar, potencializar diferenças, fazer daquilo que não somos, mas queremos ser, parte integrante de nosso mundo. Como professora, quero estar aberta, "afirmar que perceber-se do 
interior - produzir-se como eu - é perceber-se pelo mesmo gesto que já se volta para o exterior para extraverter e manifestar, para exprimir; acolhimento já é linguagem, a essência da linguagem é bondade, ou ainda, a essência da linguagem é amizade e hospitalidade."29

.-“A linguagem é sempre potência; no espaço da fala, nenhuma inocência, nenhuma segurança." ${ }^{30}$

-Não busco segurança... Mas não sou sempre a mesma... Ora quero experienciar o potencial transformador da arte com meus alunos, ora, menos otimista, acho que os alunos (assim como eu) estão apenas reproduzindo condicionamentos, trajetos emoldurados, trejeitos consumistas, trajando imitações made in china e emoções de novela. Ora penso que vou desistir... Vou embora. Adeus alunos...

-Olá prof, falando comigo?

-Olá aluno! Tu também estás aqui!

-Gosto das aulas de arte, me sinto maior... Mais próximo dos amigos... Estou aprendendo a me perceber, a botar fé em mim! Você está indo mesmo embora?

-Pode ser...

-Então... Mais uma vez... Quem se importa então?

-Me importo, mas...

-“Hei! Teacher! Leave the kids alone????"31 Não estou mesmo a fim de aprender o que vocês ensinam. Não tem nada a ver com minha vida. Para que? Ser "alguém" na vida, ter futuro... Alguém? Futuro? Haverá futuro?

-Há o presente e nossos projetos de devir. Há ainda o afeto que nos expande em abraços e nos leva a rirmos (ou chorarmos) e caminharmos juntos. Assim decido mesmo continuar sendo professora, continuar aprendendo. Tentar provocar descontinuidades, transformar as relações com a vida, fazer das aulas de arte trilhas poéticas que atravessem as paisagens contemporâneas.

-Bom...Então seguimos... nos vemos na escola, hoje à tarde, prof... -Até já!

\footnotetext{
${ }^{29}$ LÈVINAS, E. 1980, p 282. (Totalitè ET Infini, La Haye, M Nijhoff) in derrida

${ }^{30}$ BARTHES, R. 2004, p 388.

${ }^{31}$ PINK FLOYD in The Wall,
} 


\section{O Outro}

-Vou para a escola em busca do outro, o aluno... É meu desejo. Uma necessidade que não tem mais necessidades, que se reconhece na necessidade de um outro que é outrem, que não é nem meu inimigo, nem meu complemento. Um desejo que nasce em quem não carece de nada, para além de tudo que the pode faltar ou satisfazer. "A relação com o outro questiona-me, esvazia-me de mim mesmo, e não cessa de esvaziar-me, descobrindo-me possibilidades sempre novas. O desejável não preenche meu desejo, mas aprofunda-o, alimentando-me, de alguma forma, de novas formas. ${ }^{32} \mathrm{O}$ que pensas?

\section{-Eh ! Espelho! Estás ainda aí? És o meu outro!!!}

-O outro é a condição de toda percepção. É o que produz uma profundidade possível no espaço, sem a qual, as transições e inversões se tornariam incompreensíveis, e não cessaríamos de nos chocar contra as coisas, o possível tendo desaparecido. ${ }^{33}$

-A dúvida radical é se podemos evadirmo-nos do círculo mágico de nossos hábitos, de nosso modo de pensar mediado cultural e linguisticamente. ${ }^{34}$ Quero perfurar a tela de controle, espalhada em nossos olhos, negação do sensível, que faz do corpo mera aparência, da alteridade um deserto e do cotidiano, banalidade.

-Não há tela. O espaço é infinito. A arte é a criação de outras linguagens. As possibilidades estão aqui, existem dentro da linguagem que as exprime. Requerem espaço e abertura, para o outro, para outros possíveis...

-Abrir já não é ver, mas ouvir o ruído de um "aberto" que se instaura através do diferente, do estranhamento. E se a arte enriquece nossa vida, não é porque nos oferece saídas, mas, ao contrário, porque problematiza nossa relação com a realidade e apresenta muito mais perguntas do que respostas. ${ }^{35}$

-Uma relação que toca, desperta, torna sensível...

\footnotetext{
${ }^{32}$ LÈVINAS, E. 1993, p. 48

${ }^{33}$ DELEUZE, G. e GUATTARI, F. 1992, p.30.

${ }^{34}$ GADAMER, 1992,II: p 195,196.

${ }^{35}$ KONESKI, 2009, p.98..
} 
-Abrir-se ao possível é acolher, tal como acontece quando nos apaixonamos por alguém, a emergência de uma descontinuidade na nossa experiência; e construir, a partir da nova sensibilidade que o encontro com o outro proporciona, uma nova relação, um novo agenciamento. Apaixonamo-nos menos por uma pessoa do que pelo mundo de possíveis que ela carrega; relacionamo-nos no outro, menos com sue existência atualizada que com as possibilidades que o encontro com o outro faz surgir. ${ }^{36}$

-O outro. O inatual. Quando o sujeito permanece em si, suas outras dimensões permanecem-Ihe estranhas.

-Busco o outro, não para colocar-me ao seu lado como um, numa síntese, mas como "um-para-o-outro, como um-responsável-pelo-outro," e entre nós abre-se uma diferença sem fundo, uma não indiferença, que é a proximidade mesma do próximo. ${ }^{37} \mathrm{O}$ outro é a não prioridade do mesmo, do eu mesmo e de todas estas limitações.

-Eu? "Puro sinal feito a outrem; sinal feito da própria doação de sinal." 38

-Não uma identidade fechada, mas relação.

-A questão do sujeito não é uma questão de 'substância', mas de um projeto, a capacidade de receber sentido, produzir sentido, dar sentido, fazer com que seja, cada vez, um sentido novo. ${ }^{39}$

- Não há um sujeito prévio, mas processos de subjetivação, fazer-se diferente, escapar aos poderes e saberes constituídos. Produção de um modo de existência. A subjetivação não tem a ver com identidade, mas com um processo de individuação, que caracteriza um acontecimento... ${ }^{40}$

-Acredito que a percepção de nossa capacidade criadora e significadora de mundos, de nos fazermos projetos em construção é que nos confere potência. Ao entrecruzarmos, no ensino da arte, nossas vivencias, com o fazer artístico, estamos

\footnotetext{
${ }^{36}$ LAZZARATO, M. 2006, p. 18.

${ }^{37}$ Idem, p.14.

${ }^{38}$ LÈVINAS, 1993, p.17

${ }^{39}$ CASTORIADIS, 1999. p. 35.

${ }^{40}$ DELEUZE, G. 1992, p. 124- 127.
} 
construindo nosso projeto-de-ser, nossa auto-poiése. O caminho auto-poiético não existe a priori, precisa ser inventado. Implica ser criador do próprio pensamento da própria vida, questionar as maneiras habituais de percepção, formar trajetos nos quais se possa aprender a ler, percorrer e re-criar o mundo. Implica, ao mesmo tempo, reconhecer-se em contato com os outros, fazer parte de uma rede, estar aberto para o que nos circunda, desenvolver posturas de acolhimento, ser coletivo.

-Minha superfície é feita de fragmentos. Um espelho quebrado... O que está refletido aqui, são restos de uma demolição de alma, são cortes laterais de uma realidade que me foge continuamente. ${ }^{41}$

-Encontramo-nos no instante da aparição das coisas. Próximos e fragmentados... O fragmento mantém uma relação estreita com a fratura... Passa-se algo na falha das coisas, na brecha e, portanto, em sua aparição. Diante de tal aparição, deixa de haver o distanciamento do juízo. Devir... Durante um lapso de tempo bastante breve, tornamo-nos essa coisa, esse objeto ou esse instante e, em seguida, reinstala-se a dimensão da continuidade. Durante esse breve período, há descontinuidade e metamorfose...

-Devir é algo diferente da mudança e se acompanha da perda de identidade. ${ }^{42}$ Devir vida não é quando nos tomamos por um eu, é, ao contrário, ao cabo do mais severo exercício de despersonalização, quando nos abrimos às multiplicidades que nos atravessam de ponta a ponta, às intensidades que nos percorrem. Uma despersonalização de amor e não de submissão. ${ }^{43}$

-Experimento o que a transformação da subjetividade implica: criar agenciamentos, dispositivos, instituições capazes de se utilizar dessas possibilidades de vida, maneiras diversas de existir, de viver o tempo, o corpo, as sensações, o trabalho, a comunicação, outras formas de estar junto. ${ }^{44}$

-“Nessa sensação de existir existe uma outra sensação, especificamente humana, que tem a forma de um com-sentir: a existência do amigo. A amizade é instancia

\footnotetext{
${ }^{41}$ LISPECTOR, C. 1978, p. 20.

42 BAUDRILLARD 1997, p. 32.

${ }^{43}$ DELEUZE, G. 1992, p.15.

${ }^{44}$ Idem, p. $12-13$.
} 
desse com-sentimento da existência do amigo no sentimento da existência própria. Mas isto significa que a amizade tem um estatuto ontológico e, ao mesmo tempo político. A sensação de ser é, de fato, já sempre dividida com-dividida e a amizade nomeia esta condivisão." 45

-A amizade é uma relação afetuosa...

-"A amizade não é uma relação entre sujeitos, mas uma des-subjetivação no coração mesmo da sensação mais intima de si. Os amigos não condividem algo (um nascimento, uma lei, um lugar, um gosto): eles são com-divididos pela experiência da amizade. A amizade é a condivisão que precede toda divisão porque o que há para repartir é o próprio fato de existir, a própria condição de existência. a própria vida." $^{46}$

-O que é de fato, a amizade senão uma proximidade tal que dela não é possível fazer nem uma representação, nem um conceito?

-"Reconhecer alguém como amigo significa não poder reconhecê-lo como 'algo'. A amizade não é uma propriedade ou uma qualidade de um sujeito." 47

-O processo de constituição da subjetividade não tem como ponto de partida o sujeito, mas o acontecimento.

-Somos uma multiplicidade de relações que se expressam em agenciamentos coletivos. $^{48}$

-Somos acontecimentos!!!. "O sujeito é um habitus, um hábito, apenas um hábito num campo de imanência, o hábito de dizer Eu..."49

-Adquirimos hábitos contemplando, e contraindo o que contemplamos.

-Os hábitos são reproduções...

\footnotetext{
${ }^{45}$ AGAMBEM, G. 2011, p. 88-89

${ }^{46}$ Idem, p. $90-92$

${ }^{47}$ Idem, p. 85.

${ }^{48}$ LAZZARATO, M. 2006, p. 17.

${ }^{49}$ DELEUZE, G. e GUATTARI, F. 1992, p. 66.
} 
-O hábito são, por vezes, criadores. O conceito é um hábito. Há conceito em toda parte onde há habito, e os hábitos se fundem e se desfazem: são convenções. ${ }^{50}$

- Somos convenções?

-Criamos o que somos. Não mais cópias, nem modelos a reproduzir, não mais realidades a representar, não mais sombras de uma idéia perfeita. Não há uma só forma correta, nem certeza. Os modelos de ser, pintar, ensinar, aprender são nossos interlocutores, mas não verdades. Como pinceladas num papel, são ficções...

-Certeza? Era como um solo firme e seguro que ruiu e, ao perdê-lo, nos sentimos cair no vazio, pois desapareceu tudo aquilo que era sólido e ao qual nos podíamos agarrar. Mas vazio também é o nome da possibilidade.

-Percebemos que estas perdas nos propiciam a criação de novos possíveis.

-E para nós o possível se tornou mais necessário que o real porque o real, embora nos mantivesse seguros havia começado a nos asfixiar. ${ }^{51}$

\section{Devir arte?}

Existir, não como um sujeito, mas como uma obra de arte.

Deleuze

-Perceber, em cada aluno, personagens únicas de abundâncias e fertilidades. Abrir mais e mais. Trabalhar as fissuras que abrimos nas imagens e nos horizontes.

-Trabalhar com imagens?

-Também.

-Leitura de imagens?

-Mais do que ler imagens nos relacionamos com elas como o lugar de uma experiência da ordem do virtual. A imagem não é fixa, assim como o sujeito que a cria e que a vê, está sempre em processo. Ensinar... Aprender... Interromper o que já sabemos, dar uma palavra a ler como se ainda não soubéssemos lê-la. Devolver às palavras esta ilegibilidade que lhes é própria e que perderam ao se inserir demasiado comodamente em nosso sentido comum. Problematizar o evidente, criar

\footnotetext{
${ }^{50}$ Idem, p 137.

${ }^{51}$ LARROSA, J.2003. p. 164.
} 
estranhamentos, devolver certa obscuridade ao que parece claro, abrir uma distancia entre o saber e o pensar. ${ }^{52}$

-Não se pôr no lugar das grandes epistemes que são como a verdade, mas em um lugar vigilante, guardando a linguagem para que não caia em dogmatismos, arrogâncias, em Últimos significados. ${ }^{53}$

-Nas aulas, ao trabalhar com arte contemporânea, busco gerar desequilíbrios nos modelos pré-concebidos de percepção, nas relações entre obra e observador, imagem e representação.

\section{-Como?}

-Possibilitando experiências artísticas que desafiam concepções instituídas sobre a relação sujeito e mundo. Na medida em que interior e exterior, sujeito e objeto, real e virtual se confundem numa interconexidade, nos afastamos de definições precisas e mergulhamos no campo da multiplicidade, da transitoriedade. A imagem transpõe o campo da representação e se estabelece como processo capaz de produzir diferença. Um saber pluralizado, continuamente levado a multiplicar-se: não destruído, mas deslocado.

-O seu novo lugar é a ficção.

-A ficção é também um esvasiar-se. Ela começa com o que vê e, descobre assim, a força de um começo.

-Ela é acolhimento e não o poder de decifrar e de analisar, ou de retornar aquém desnudando. Ela não compreende. É ignorante... Inocência. Simplicidade que toma a imagem tal qual se oferece, sem passado, sem certezas. ${ }^{54}$

-Sem passado...

-Sim... Busca esquecer nosso saber, romper com nossos hábitos de percepção e pensamento, para possibilitarmo-nos um ato poético súbito. "O poeta nasce da figura que recebe, cada vez, a primeira vez, ele se renova nesta breve novidade que introduz um intervalo na duração e inaugura um outro tempo." 55

52 LARROSA, J, 2004, p. 16.

${ }^{53}$ BARTHES, R. 2004, p. 226.

${ }^{54}$ BLANCHOT, M. 2010, p. 58.

${ }^{55}$ Idem, p. 59. 
-“A poesia é sempre retorno, mas um retorno que é adiamento, retenção e não nostalgia ou busca por uma origem; é um caminhar, mas não um simples marchar para frente, é um passo suspenso. Suspender o passo entrever um limiar inapreensível entre um ainda não e um não mais." ${ }^{56}$ Habitar o tempo da poesia... da imagem... A imagem é também um enigma, uma pergunta, solicita toda nossa aptidão a responder.

-Mas ela é, também, resposta, e repercute em nós como aquilo que extrai de nós a resposta que ela nos exorta a ser. Este desdobramento parece ser sua natureza... Ela é múltipla, não apenas signo e significado, mas figura do não figurável, forma do informal, reanimando em nós, a multiplicidade em que nos dividimos e nos juntamos indefinidamente.

-A imagem treme, estremecimento daquilo que oscila e vacila, e sai constantemente de si própria, pois não há nada onde ela seja ela própria, sempre já fora de si própria e sempre interior desse exterior. ${ }^{57}$

-"A imagem fala-nos, e parece que nos fala intimamente de nós. A felicidade da imagem é que ela é um limite perto do indefinido. Pelo que existe de inflexível num reflexo, cremo-nos senhores da ausência convertida em intervalo. Ficamos felizes em encontrar a eternidade transparente do irreal." 58

-Não foi isso que nos ensinaram, não é? A imagem, segundo nossos condicionamentos, vem depois do objeto: ela é sua representação; vemos, depois imaginamos. Depois do objeto é que viria a imagem.

-Depois?

-“Depois significa que cumpre, em primeiro lugar, que a coisa se distancie para deixar-se recapturar... A coisa estava aí, que nós apreenderíamos no movimento vivo de uma ação compreensiva e, tornada imagem, ei-la instantaneamente convertida no inapreensível, inatual, impassível, não a mesma coisa distanciada mas essa coisa como distanciamento, a coisa presente em sua ausência... Na imagem, o objeto aflora de novo algo que ele dominara para ser objeto, contra o qual se

\footnotetext{
${ }^{56}$ AGAMBEM, G. 2009, p. 20

${ }^{57}$ Idem, p.66.

${ }^{58}$ BLANCHOT, 1987, p.256
} 
edificara e definira, mas agora que seu valor, seu significado, estão suspensos, agora que o mundo o abandona à ociosidade e o coloca de lado, a verdade nele recua, o elementar reivindica-o, empobrecimento, enriquecimento que o consagram como imagem." 59

-“A intensidade da imagem é proporcional à sua descontinuidade e à sua abstração máxima, ou seja, a da decisão de denegação do real. Criar uma imagem consiste em ir retirando do objeto todas as suas dimensões, uma a uma: o peso, o relevo, o perfume, a profundidade, o tempo, a continuidade e, é claro, o sentido. A custo dessa desencarnação, desse exorcismo, a imagem ganha esse fascínio a mais, essa intensidade, torna-se transparente a uma forma de sedução mais sutil." ${ }^{0}$

-Viver um evento em imagem não é desligar-se desse evento, desinteressar-se dele, como propunha o ideal sereno da arte clássica, mas tampouco é envolver-se nele por uma decisão livre: é deixar-se prender nele, passar da região do real, onde nos mantemos a distância das coisas a fim de melhor dispor delas, para essa outra região onde a distância nos detém, essa distância que é então profundidade indisponível, lonjura inapreciável que se torna como que a potência soberana e derradeira das coisas. ${ }^{61}$

-Nem desinteressado, nem envolvido... Nem tão perto, nem tão longe... Nem impessoal, nem pessoal... Será ensimesmado?

- Não faço arte para falar de mim. Não escrevo para vasculhar meus arquivos pessoais, meus dramazinhos passageiros. Acho que criar arte é um devir alguma coisa. Não se desenha, por exemplo, pelo simples fato de desenhar. Desenhar é devir, devir o que bem entender. Acho que se desenha porque algo da vida se passa em nós. Desenha-se para a vida... ${ }^{62}$ Vida que me perturba e me deixa trêmulo com seus desafios que parecem necessários ao meu amadurecimento... Desenho, pinto, escrevo, para aprender. ${ }^{63}$

\footnotetext{
59 idem, p. 257.

${ }^{60}$ BAUDRILLARD, 1997, p. 32.

${ }^{61}$ BLANCHOT, 1987, p. 262.

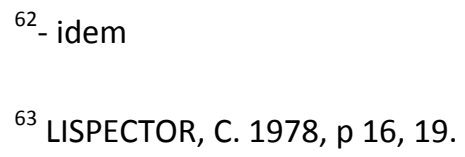


-Será que podemos dizer que aprendemos com a arte?

-Penso que, se aprendemos com a arte, e aprendemos, não é porque ela explica o mundo, mas porque ela o problematiza, questiona, nos põe diante de um impasse, diante do que não conseguimos trazer à luz. Ironicamente, uma aprendizagem pela "não-aprendizagem", se quisermos comparar com tudo o que sabemos do que seja aprender. Apreender, no senso comum, é segurar, agarrar, mas aqui, é justamente ver escorregar das mãos todas as possibilidades de agarrar. Estar diante do "abismo". Um desafio. ${ }^{64}$

-Num cotidiano onde a velocidade varre a presença, o olhar poético atravessa a dimensão utilitária e unívoca da realidade e cria intervalos, pausas, silêncios, repousos.

-A experimentação poética metamorfoseia aquilo que não cabia nos lugares do mundo. Abre fissuras no campo fechado da escola. Faz caber coisas no mundo que antes não cabiam, fazendo-nos ver coisas que não conseguíamos perceber.

-Arte, nos encontramos quando nossa identidade nela se perde.

-Devir arte, minha própria obra. Não objeto ou sujeito, mas obra. Não artista ou professora, mas arte. Obra que faz aparecer o que havia desaparecido no olhar já formatado.

-O devir, por desfazer normas e crenças, lança o homem no vazio, levando-o a compreender a existência apenas como experiência, como uma ponte, passagem. $\mathrm{O}$ que há de grande no homem é ser ponte, e não meta. O que pode amar-se no homem, é ser uma transição e um ocaso. ${ }^{65}$

- Viver poesia, o invivido, abrir-se a um lugar que a vida não prepara, mas o poeta cria. ${ }^{66}$ Uma atitude política...

-Política?

-Sim... A arte fala de uma região outra, de onde nos vem uma força nova! ${ }^{67}$ Ela nos move e transforma. Todos já tivemos experiências dessas na vida: ouvir uma

${ }^{64}$ KONESKI, A. 2009, p 102.

\footnotetext{
${ }^{65}$ NIETZSCHE, F. 1998, p 31.

${ }^{66}$ BLANCHOT, M. 2010, p. 61

${ }^{67}$ Idem, p. 12.
} 
música, ver um filme ou um quadro, que nos marca de uma maneira irreversível, algo muda, algo se quebra, algo se abre. É nesse sentido que a arte é política. É menos uma arte sobre política e mais a idéia de uma política da arte.

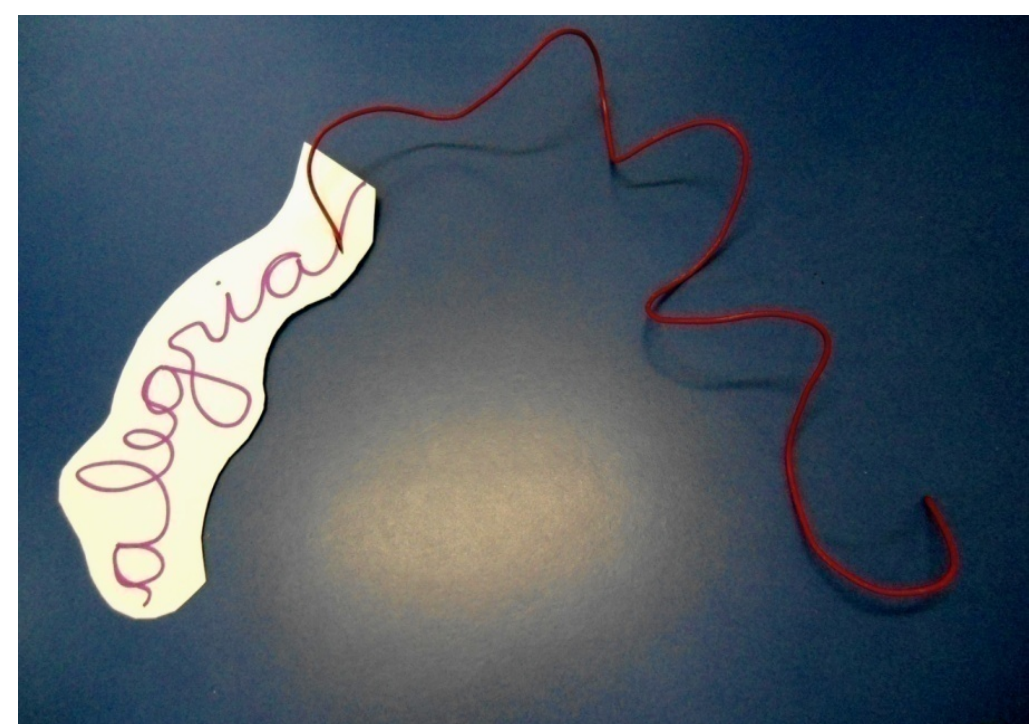

Figura 4- Linha de fuga ou fuga da linha? M. C. Diederichsen tim, 2011.

-Transformamos, pela prática artística, os ambientes de nossas mentes... Criamos terras insondáveis e paradoxais que desestabilizam percepções e afetos, superando fronteiras, reencontrando potencias, adentrando nossa natureza ilimitada. $O$ ato criador inventa fagulhas, linhas de fuga, diferentes maneiras de se relacionar com as realidades instituídas. Concordo... . É também um ato político...

-A perspectiva artística é certamente a mais desviante, ela se afasta em tal intensidade dos estreitamentos habituais das praticas escolares que equivale a uma completa reinvenção dos meios. No ensino da arte, nos deparamos com o apaixonante desafio: abrirmo-nos a novas formas de viver e pensar o presente, evitando que nossas propostas resultem simplesmente num endosso dos modelos de produtividade, eficiência e competitividade da sociedade neo-liberal. O trabalho com arte pode ser uns dos mais poderosos instrumentos críticos de que dispomos hoje para ver além das bordas, para pensar e transformar o modo como as sociedades contemporâneas se constituem, se reproduzem e se mantêm. ${ }^{68}$

\footnotetext{
${ }^{68}$ MACHADO, A. 2004, p.6.
} 
-Penso que ela provoca, instiga e reaviva nossos sentidos, descondicionando-os, retirando-os de uma ordem preestabelecida e sugerindo ampliadas possibilidades de viver e de se organizar no mundo. ${ }^{69}$ Arte é o exercício experimental da liberdade. ${ }^{70}$ -A arte é um conhecimento que não se resolve em interpretações, em explicações. ${ }^{71}$ -Não interpretar?

-Interpretar o artista não é traí-lo? Interpretá-lo fielmente não é suprimi-lo? Dizer claramente o que ele disse de modo obscuro, não é revelar o mistério de sua fala obscura.? ${ }^{72}$

-Fala, pensamento e conhecimento obscuros... Como vai ficar a mente destes alunos? A escola não busca exatamente o contrário? Iluminar?

-Penso que é importante trabalharmos à luz e à sombra.... Não é assim na vida? Dia, noite... Entendo a dificuldade que pode ser para nós, relacionarmo-nos com a tradição desta maneira, pois isso implica libertar-se das seguranças e, paradoxalmente, ter um bom conhecimento dela para poder descartá-la. Implica ainda, poder, no confronto com ela, perceber a fecundidade de descartá-la (paradoxalmente conservando-a) cultivar e acolher, outros modos de ser. ${ }^{73}$

-Libertar-se das seguranças... O que pode então a arte oferecer, inseguranças? Nada mais?

-"Não se trata de dizer que a arte nada nos oferece, mas de dizer que o que ela nos oferece não é mais, por determinação de nossos velhos hábitos, o que esperamos dela. Ou, não se trata de dizer que a arte nada "diz", mas de afirmar que ela diz o inefável, esse ruído indizível, que se faz vestígios, que acumula questionamentos. E perceber que neste atestado estranhamento que ela nos causa está a sua profundidade, pois desmonta a pretensão do saber, da luminosidade, pois sua profundidade, está, justamente, na obscuridade."74

\footnotetext{
${ }^{69}$ CANTON, K. 2009, p 12.

${ }^{70}$ PEDROSA, M, in CANTON, K. 2009, p 11.

${ }^{71}$ KONESKI, A. p. 100.

72 LÈVINAS .1994, p. 44.

${ }^{73}$ KONESKI. A. p. 101.

${ }^{74}$ Idem.
} 


\section{Antes de partir}

-Agora é hora de eu ir... Tu, espelho, és um interlocutor maravilhoso...

-São só algumas reflexões... Palavrinhas à toa...

-Fiquei mais motivada a realizar a visita à exposição de arte contemporânea que havíamos agendado para hoje... Propiciar aos alunos o contato estas obras, colocálos frente a frente com um ensinamento outro, de outro modo de ser, deixá-los serem atravessados pela descontinuidade que a arte instaura em nossa maneira comum de perceber o mundo...

-Frente a frente com um estranhamento que abre espaço para acolher o ruído da riqueza inominável que somos.

-Propiciar que se posicionem diante do ruído desta arte, diante da sua problematização, de seu vazio que lhe tira qualquer palavra que poderiam pronunciar a respeito dela, que percebam, talvez, a fecundidade do ruído que a arte contemporânea aponta, desse estar para mais além do que podemos pensar, ou desse "muito próximo" que nos tira o sentido do compreender. Isso significa estar distante das abordagens que a reduzem a um formalismo ou a um conteudismo. ${ }^{75}$ -Quem sabe, proporcionar-Ihes a possibilidade de serem contemporâneos, para que, como Perseu, através dos espelhos enviesados da arte, possam enxergar o mundo, poetizá-lo e transformá-lo.

-Sermos contemporâneos... Pertencer a nosso tempo implica em não coincidirmos perfeitamente com ele, é exatamente através deste deslocamento que nos tornamos capazes de perceber, apreender e recriar nosso tempo. Aqueles que coincidem muito plenamente com a época, não conseguem vê-la. ${ }^{76}$

-Depois de ter passado pela prova da insensibilidade política, se curvado às duras lógicas do produtivismo, às máscaras insanas da eficiência econômica, não estariam as sociedades e as escolas redescobrindo os encantos da distensão, da retomada do imaginário, de formas de ação que privilegiam a intuição, o sensível, a experiência, de reentrada da estética como possibilitadora da reinvenção da vida em bases mais felizes? ${ }^{77}$

\footnotetext{
${ }^{75}$ KONESKI, A, 2009, p.100.

${ }^{76}$ AGAMBEM, G, 2008 p. 59.

${ }^{77}$ MEIRA, M. 2003, p61.
} 
-Será mesmo possível?

-Sim... Ir caminhando, passo a passo, criando pequenos desvios nas narrativas dominantes... Mesmo na sala de aula, as ações artísticas instauram instrumentos desviantes e formas de ampliação de campos perceptivos, de elaboração de linguagens próprias e interativas, potencializadoras da vida. Talvez, um dos papéis mais importantes da arte, numa escola, seja justamente a recusa de submeter-se à lógica de um projeto educativo padronizado e a reinvenção de procedimentos, funções e finalidades. Longe de deixar-se escravizar por uma norma, por um modo estandardizado de ensinar e aprender, as experiências artísticas podem reinventar maneiras de imaginar, criar, compartilhar e poetizar nosso cotidiano. ${ }^{78}$

-Será que estamos superestimando o poder da arte? Vivemos em um mundo sob risco de desaparecimento, em uma crise ambiental aguda, somos uma humanidade beirando sua autodestruição, se lançando numa espécie de abismo, num espaço desconhecido...

-Mas é esse mesmo outro espaço desconhecido e não contaminado com os poderes e suas hostilidades, que pode vir a ser o terreno da hospitalidade e do compartilhamento ${ }^{79}$.

-Hospedar plenamente a vida... Compartilhar, com-existir... Muito bom para um espelho...

-E a vida é mais do que nós... A arte, uma experiência que nos ultrapassa, toca o infinito.

-Os atos artísticos transbordam a força daqueles que são atravessados por eles. ${ }^{80}$

\section{REFERÊNCIAS BIBLIOGRÁFICAS}

AGAMBEM, Giorgio. O que é o contemporâneo e outros ensaios. Tradutor: HONESKO, Vinicius. Chapecó: Argos, 2009

BACHELARD, Gaston. A Poética dos Devaneios. Tradutor: DANESI, Antonio de Padua. $3^{\mathrm{a}}$. Ed. São Paulo: Martins Fontes,2009.

\footnotetext{
${ }^{78}$ MACHADO, A. 2004, p.5.

${ }^{79}$ DERRIDA, J. 2004, p. 17.

${ }^{80}$ DELEUZE, G e GUATARRI, F. 1992, p.213.
} 
A Poética do Espaço. São Paulo: Martins Fontes, 2002.

BAUDRILLARD, Jean. A arte da desaparição. Rio de Janeiro: Editora UFRJ, 1997.

BARTHES, Roland. O rumor da Língua. Tradutor: LARANJEIRA, Mario. 2a . Ed. São Paulo: Martins Fontes, 2004.

BLANCHOT, Maurice. O espaço Literário. Tradutor: CABRAL, Alvaro. Rio de Janeiro: $\quad$ Rocco, 1987.

A conversa Infinita 3: a ausência do livro. Tradutor: MOURA Jr, João. São Paulo: Escuta, 2010.

CANTON, Katia. Temas da Arte Contemporânea. São Paulo: Martins Fontes, 2009.

CALVINO, Italo. Seis propostas para o próximo milênio. São Paulo: Companhia das Letras, 1991.

CASTORIADIS, in PENA-VEGA ; NASCIMENTO. (Org). O Pensar Complexo. Rio de Janeiro: Garamond,1999.

CHEREM, Rosangela. Um intelectual de extimidades (Entrevista com Antelo, Raul). In Palindromo. Florianópolis: CEART, no. 3, Junho 2010.

DELEUZE, Gilles. Diferença e Repetição. Tradutores: ORLANDI, Luis; MACHADO, Roberto. 2a . Ed. São Paulo: Graal, 2009.

DELEUZE, Gilles; GUATTARI, Felix. Mil Platôs. Capitalismo e esquizofrenia. 1. Tradutores:GUERRA NETO, Aurélio; COSTA, Célia. Rio de Janeiro: Ed 34, 2000.

O que é filosofia. Tradutores: PRADO Jr, Bento; ALONSO MUÑOZ, Alberto. Rio de Janeiro: Ed 34, 1992.

DERRIDA, Jacques. Adeus a Emmanuel Lèvinas, Perspectiva, 2008

Anne Dufourmantelle convida Jaques Derrida a falar da hospitalidade.

Tradução ROMANE Antonio. São Paulo: Escuta: 2003.

DERRIDA, Jacques; ROUDINESCO, Elisabeth. De que amanhã... Rio de Janeiro: Zahar, 2004.

GUATTARI, Felix. As três ecologias. Tradutora BITTENCOURT M. Cristina. Campinas: Papirus, 1990.

KASTRUP, Virginia. A invenção de si e do mundo. Belo Horizonte: Autêntica, 2007. KONESKI, Anita. A estranha fala da arte contemporânea e o ensino da arte. In Palindromo, Florianópolis: CEART, n.1. junho 2009. 
LARROSA, Jorge. Linguagem e educação depois de Babel. Tradutora: FARINA, Cynthia. Belo Horizonte: Autêntica, 2004. Pedagogia Profana. Tradutor: VEIGA-NETO, Alfredo. 5. Ed. Belo Horizonte: Autêntica, 2010.

LAZZARATO, Maurizio. As Revoluções do capitalismo. Tradutora: CORSINI, Leonora. Rio de Janeiro: Civilização Brasileira, 2006.

LÉVINAS, Emmanuel. Humanismo do outro homem. Tradutor: PIVATTO, Pergentino. (coord). Petrópolis: Vozes, 1993. Sobre Blanchot, Madrid: Editorial Trotta, 2000. La realidad e su sombra. Madrid: Editorial Trotta, 2001. Totalitè et Infini. La Haye: M Nijhoff, 1980.

LIPOVETSKY, Gilles. e SERROY, Jean. A cultura-mundo. Tradutora: MACHADO, Maria Lucia. São Paulo: Companhia das Letras, 2011.

LISPECTOR, Clarice. Um sopro de vida- Pulsações. Rio de Janeiro: Nova Fronteira, 1978.

LOPES, Denilson. A delicadeza. Brasília: EUB, 2007.

MACHADO, Arlindo, Arte e mídia: aproximações e distinções. Revista eletrônica ecompós: disponível em http://www.compos.org.br/e-compos, 2004. Acesso em 07.07.2011.

MACHADO, Roberto. Deleuze, a arte e a filosofia. Rio de Janeiro: Zahar, 2009.

MEIRA, Marly. Filosofia da Criação. Porto Alegre, Mediação: 2003. Educação estética, arte e cultura do cotidiano. In A Educação Do Olhar, PILLAR DUTRA, Analice, (organizadora), Porto Alegre: Mediação, 1999. NIETZSCHE, Friedrich. Obras Incompletas. São Paulo: Nova Cultural, 1988. A gaia ciência. São Paulo: Companhia das letras, 2002 SKLIAR, Carlos. Derrida e a Educação. Belo Horizonte: Autentica, 2008 